\title{
Crustal configuration of NW Himalaya based on modeling of gravity data
}

\author{
Ashutosh Chamoli ${ }^{*}$, AK Pandey ${ }^{1}$, VP Dimri ${ }^{1}$ and P Banerjee ${ }^{2}$ \\ 1 National Geophysical Research Institute, Hyderabad- 500 007, INDIA \\ 2 Wadia Institute of Himalayan Geology, Dehradun- 248 001, INDIA \\ *For correspondence, email: chamoli.a@gmail.com
}

The crustal structure of the Himalayan fold-thrust belt in NW Himalaya is constrained using spectral analysis, wavelet transform (WT) and forward modeling of the Bouguer gravity anomaly. The data covers the Himalayan range from the Sub Himalayan zone in the hanging wall of Himalayan Frontal Thrust (HFT) to the Karakoram fault across the Indus Tsangpo Suture Zone (ITSZ), along about $450 \mathrm{~km}$ long (projected distance), the Kiratpur-Manali-Leh-Panamik transect. The spectral analysis of power spectrum of the gravity data yielded three layer interfaces. The short wavelength data is modeled on the basis of density contrast across the litho-tectonic boundaries and regional structural geometries along the profile section. The average depth and location obtained using the wavelet transform (WT), which shows good correlation with the major mapped tectonic boundaries including intracrustal/subcrustal faults in space scale domain. The long wavelength gravity data is analysed using coherence method for isostatic compensation to obtain the average depth of effective elastic thickness. The Moho configuration and the locus of flexure of Indian crust is constrained using forward modeling incorporating information from other studies. The Moho depth increases from 40 to $75 \mathrm{~km}$ towards north with the locus of flexure of Indian crust beneath the Lesser Himalayan zone. The combination of forward modeling and WT analysis of the data gives insight into the subsurface extent and geometry of regional structures for the first time from the NW Himalaya. 